\title{
Effect of variable fluid properties on the hydrodynamic and thermal characteristics of parallel flow microchannel heat exchanger
}

\author{
https://doi.org/10.32792/utq/utj/vol10/4/6
}

\author{
Dr. Mushtaq Ismael Hasan \\ Mechanical Engineering Department, College of Engineering, Thi - Qar \\ University
}

\begin{abstract}
In this paper the parallel flow microchannel heat exchanger is numerically investigate and the effect of treating the properties of fluids as variables with temperature compared with constant fluid properties assumption on its performance is studied.

A numerical simulation is made to solve 3D Navier stock equations in two fluids with temperature dependent properties and 3D energy equation in two fluids and solid walls taking into account the effect of entrance region and axial conduction in the walls.

The properties entered to the main program by relations as a function of temperature using subroutines written to calculate the properties at the end of each iteration.

The results obtained show that, treating the properties as a temperature dependent gives higher overall performance since it leads to obtain lower pressure drop and higher effectiveness compared with constant properties assumption.
\end{abstract}

Keywords: Fluid properties, microchannel heat exchanger, parallel flow, thermal performance, hydrodynamic characteristics

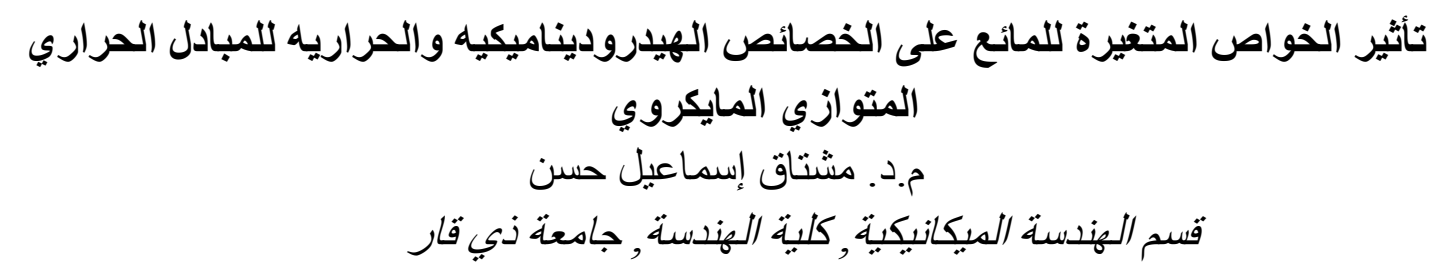


University of Thi-Qar Journal Vol.10 No.4 Dec 2015

Web Site: https://jutq.utq.edu.iq/index.php/main Email: journal@jutq.utq.edu.iq

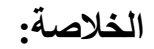

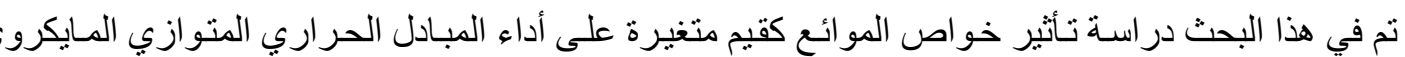

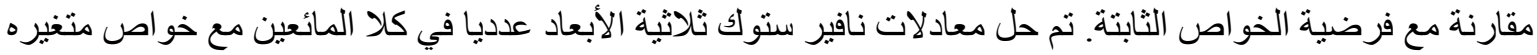

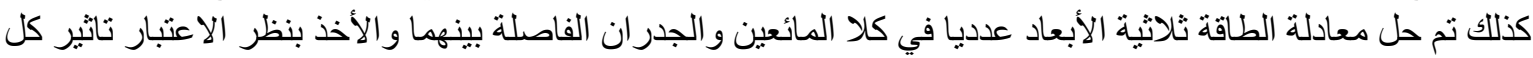
من منطقة الدخول و التوصيل الحرارئ تارئ الابعاد المحوري في في الجدران.

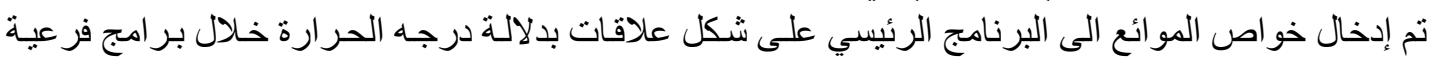

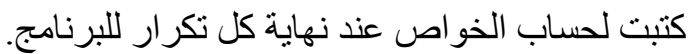

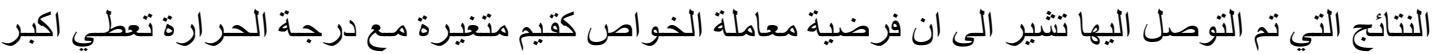

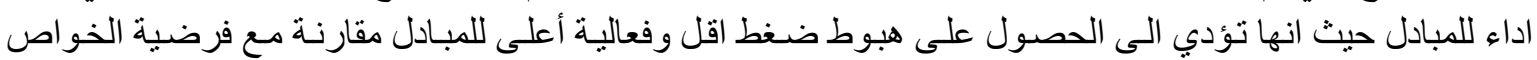

\section{Nomenclature:}

\begin{tabular}{|c|c|c|}
\hline Quantity & Symbol & Unit (SI) \\
\hline Specific heat & $C_{p}$ & $\mathrm{~J} /(\mathrm{kg} \mathrm{K})$ \\
\hline Channel height & $H$ & $\mathrm{~m}$ \\
\hline Thermal conductivity & $k$ & $\mathrm{~W} / \mathrm{m} \mathrm{K}$ \\
\hline Channel length & $L$ & $\mathrm{~m}$ \\
\hline Mass flow rate & $m$ & $\mathrm{~kg} / \mathrm{s}$ \\
\hline Pressure & $P$ & $\mathrm{~Pa}$ \\
\hline Heat transfer rate & $q$ & $\mathrm{~W}$ \\
\hline $\begin{array}{l}\text { Maximum heat transfer } \\
\text { rate }\end{array}$ & $q_{\max }$ & $\mathrm{W}$ \\
\hline Temperature & $T$ & $\mathrm{~K}$ \\
\hline Separating wall thickness & $t$ & $\mathrm{~m}$ \\
\hline Fluid x-component velocity & $u$ & $\mathrm{~m} / \mathrm{s}$ \\
\hline Fluid y-component velocity & $v$ & $\mathrm{~m} / \mathrm{s}$ \\
\hline Volumetric flow rate & $V$ & $\mathrm{~m}^{3} / \mathrm{s}$ \\
\hline Average velocity & $\mathrm{V}_{\text {in }}$ & $\mathrm{m} / \mathrm{s}$ \\
\hline Fluid z-component velocity & $w$ & $\mathrm{~m} / \mathrm{s}$ \\
\hline Channel width & $W_{c h}$ & $\mathrm{~m}$ \\
\hline Axial coordinate & $x$ & $\mathrm{~m}$ \\
\hline Vertical coordinate & $y$ & $\mathrm{~m}$ \\
\hline Horizontal coordinate & $z$ & $\mathrm{~m}$ \\
\hline $\begin{array}{l}\text { Pressure drop across heat } \\
\text { exchanger }\end{array}$ & $\Delta P$ & $\mathrm{~Pa}$ \\
\hline
\end{tabular}


Greek symbols

\begin{tabular}{|l|c|c|}
\hline Performance index & $\eta$ & $1 / \mathrm{Pa}$ \\
\hline $\begin{array}{l}\text { Heat exchanger } \\
\text { effectiveness }\end{array}$ & $\varepsilon$ & - \\
\hline Dynamic viscosity & $\mu$ & $\mathrm{Pa} / \mathrm{s}$ \\
\hline Density & $\rho$ & $\mathrm{kg} / \mathrm{m}^{3}$ \\
\hline
\end{tabular}

\section{Subscripts}

\begin{tabular}{|l|c|}
\hline \multicolumn{1}{|c|}{ Quantity } & Symbol \\
\hline Cold fluid & $\mathrm{c}$ \\
\hline Hot fluid & $\mathrm{h}$ \\
\hline Inlet & $\mathrm{I}$ \\
\hline Maximum value & $\mathrm{max}$ \\
\hline Outlet & $\mathrm{o}$ \\
\hline Solid & $\mathrm{s}$ \\
\hline
\end{tabular}

\section{Introduction:}

Fluid properties play an important role in cooling applications. In microchannels due to its short length, the effect of entrance region cannot be ignored. Moreover, temperature dependence of fluid properties can also play an important role in the development of the velocity and temperature fields.

There are two ways to deal with the properties of fluid and introducing it into calculations, the first way is by assuming it as constant values calculated according to the mean temperature of fluid which is the most assumption used in the literature. The second is by assuming the properties as variable values varied with temperature and calculated using suitable relations as a function of temperature through the computations.

To the author's knowledge no systematic studies are reported in the literature taking into account the effect of properties variation on the performance of microchannel heat exchangers.

Dong and Poh-Seng (2003) [1] numerically analyzed the characteristics of flow in microchannels. The 3D, steady state convection -conduction conjugate problem is solved with CFD software Package Fluent 6.0. The effects of temperature dependence of fluid thermo physical properties on the performance of the microchannel heat sink were examined. It was shown that, in contrast to the results from constant properties consideration, which is the common practice in literature, the temperature dependent properties produced lower friction factor.

Al-Bakhet and Ahmad (2005) [2] numerically investigated the flow and heat transfer in parallel flow microchannel heat exchanger with constant properties. They used the idea of a hybrid approach, in which the nonlinear momentum equations for one or two channels were solved by using CFD codes. The velocity field was inputted into a user developed 
code for solving the energy equation. They studied the heat transfer for thermally developing laminar flow in two parallel rectangular channels which represent the complete parallel flow microchannel heat exchanger. From the results in the entrance region the developing velocity profiles lead to higher values of the overall heat transfer coefficient.

Nonino et al (2006) [3] numerically investigated the effect of temperature dependent viscosity in simultaneously developing laminar flow of a liquid in straight duct of arbitrary but constant cross-sections with constant wall temperature boundary condition. Viscosity has been assumed to vary with temperature according to an exponential relation, while the other fluid properties have been held constant. They found that, in the laminar forced convection in the entrance region of straight duct, the effect of temperature dependent viscosity cannot be neglected in a wide range of of operative conditions.

Del et al (2007) [4] studied the effects of viscous dissipation and temperature dependent viscosity in both thermally and hydro dynamically simultaneously developing laminar flow of liquids in straight microchannels of arbitrary, but constant cross-section. The viscosity is assumed to vary linearly with temperature, while the other fluid properties are held constant. Uniform wall temperature boundary condition was used. A finite element procedure is employed for the solution of the momentum and energy equations in two-dimensional domain corresponding to the cross-section of the channel. They computed axial distribution of the local Nusselt number and of the apparent fanning friction factor for ducts of the considered cross -section. Numerical results confirm that in the laminar forced convection in straight microchannels, both temperature dependence of viscosity and viscous dissipation effects cannot be neglected in a wide range of operative conditions.

Nitin et al (2009) [5] investigated numerically the influence of property variation of gas (air) in laminar forced convection with entrance effect. They used two - dimensional micro - sized geometry (with axisymmetry) with constant wall heat flux. They found that the $\mathrm{Nu}$ shows significant deviation from conventional theory.

Mushtaq et al (2009) [6] used the nanofluid as a cooling fluid in a counter flow microchannel heat exchanger with constant fluid properties and they found that, using these types of fluids instead of pure fluids leads to increase the thermal performance of this heat exchanger by increasing its effectiveness and the rate of heat transfer without extra increase in the pressure drop across heat exchanger associated with using the nanofluid. Also they found that using nanofluid lead to increase the overall performance of counter flow microchannel heat exchanger compared with using pure fluids.

In this paper a numerical study is made to investigate the effect of fluid properties variation on the performance of parallel flow microchannel heat exchanger.

\section{Mathematical model:}

The physical model of the problem is shown in Fig.1 which shows the parallel flow microchannel heat exchanger (PFMCHE) which consists of square channels with hot and cold fluids. The difficulties in this model are that the flow is developing and heat transfer is conjugated where the 3D energy equation that must be solved for the two fluids and solid wall simultaneously. Solving complete heat exchanger numerically needs a huge of CPU 
time and is complicated. Due to the geometrical and thermal symmetry between channel's rows, an individual heat exchange unit which consists of two channels (hot and cold) and separating wall will be considered as shown in Fig. 2 to represent the complete PFMCHE and give an adequate indication about its thermal performance.

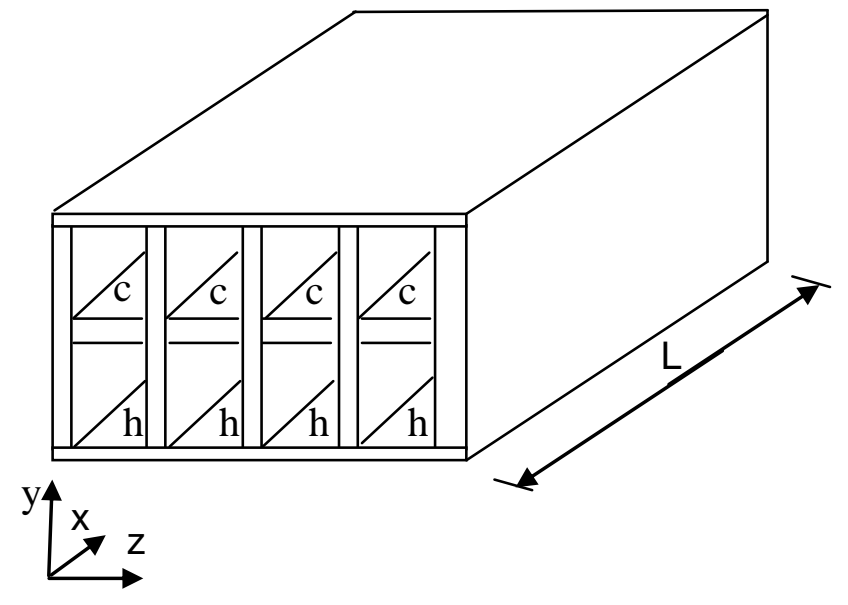

Fig.1 A schematic model of the parallel flow MCHE

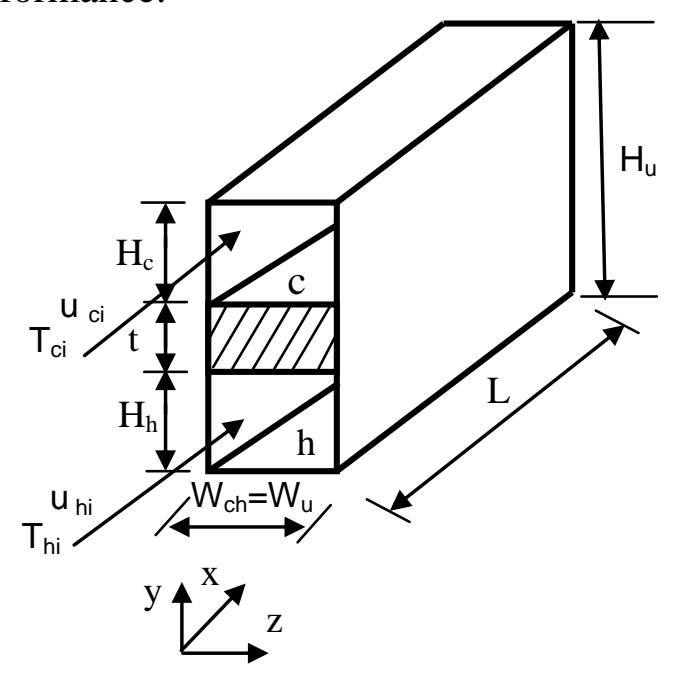

Fig. 2 A schematic of heat exchange unit

\section{3-1. Governing equations:}

The problem under consideration concerns the forced convection through the microchannels of parallel flow microchannel heat exchanger. Heat transfer in the heat exchange unit is a conjugate process combining heat conduction in the solid wall and convection in the working fluids. The system of equations governs the present model consists of continuity, momentum and energy equations which are written below in general form [7], [8]:

For fluid regions:

$$
\begin{aligned}
& \frac{\partial \rho}{\partial t}+\nabla(\rho \vec{V})=0 \\
& \frac{D(\rho \vec{V})}{D t}=-\nabla P+\nabla(\mu \nabla \vec{V}) \\
& \frac{D(\rho C p T)}{D t}=\nabla(k \nabla T)
\end{aligned}
$$

For solid region (walls):

$$
\begin{aligned}
& \vec{V}=0 \\
& \nabla^{2} T_{s}=0
\end{aligned}
$$

With the assumptions that, the flow is steady state laminar and incompressible with temperature dependent properties. Also the free convection and radiation from the outer walls of heat exchanger are negligible. 


\section{3-2. Model boundary conditions:}

The boundary conditions used are:

\section{For fluids:}

At the channels inlet the velocity component normal to the channels inlet surface and the fluid inlet temperature are specified.

At $\mathrm{x}=0$

$u_{j}=u_{j . i n}, v_{j}=w_{j}=0, T_{j}=T_{. j . i n}$

At the channel exit, fully developed flow is assumed.

At $\mathrm{x}=\mathrm{L}$

$\frac{\partial u_{j}}{\partial x}=0$

$\mathrm{v}_{\mathrm{j}}=\mathrm{w}_{\mathrm{j}}=0, \frac{\partial T_{j}}{\partial x}=0$

At the channels outer side walls, the no - slip and adiabatic boundary conditions are imposed.

At $\mathrm{z}=0, \mathrm{~W}_{\mathrm{ch}}$

$$
\mathrm{u}_{\mathrm{j}}=\mathrm{v}_{\mathrm{j}}=\mathrm{w}_{\mathrm{j}}=0, \quad \frac{\partial T_{j}}{\partial z}=0
$$

At the symmetry (half) of two channels, the zero shear stress and adiabatic boundary conditions are applied.

$$
\begin{aligned}
& \text { At } \mathrm{y}=\left(\mathrm{H}_{\mathrm{h}} / 2\right),\left(\mathrm{H}_{\mathrm{h}}+\mathrm{t}+\mathrm{H}_{\mathrm{c}} / 2\right) \\
& \frac{\partial u_{j}}{\partial y}=\frac{\partial v_{j}}{\partial y}=\frac{\partial w_{j}}{\partial y}=0 \quad \frac{\partial u_{j}}{\partial y}=0, \frac{\partial T_{j}}{\partial y}=0
\end{aligned}
$$

At the two sides of the wall separating two channels, the conjugate heat transfer boundary condition is used.

At $\mathrm{y}=\mathrm{H}_{\mathrm{h}},\left(\mathrm{H}_{\mathrm{h}}+\mathrm{t}\right)$

$-k_{j} \frac{\partial T_{j}}{\partial y}=-k_{s} \frac{\partial T_{S}}{\partial y}$

For solid walls $\left(\mathrm{H}_{\mathrm{h}} \leq \mathrm{y} \leq \mathrm{H}_{\mathrm{h}}+\mathrm{t}\right)$ :

At the outer sides of solid wall the adiabatic boundary is used.

At $\mathrm{x}=0, \mathrm{~L}$

$\frac{\partial T_{S}}{\partial x}=0$

At $\mathrm{z}=0, \mathrm{~W}_{\mathrm{ch}}$

$\frac{\partial T_{S}}{\partial z}=0$

At the fluid - solid interface, the conjugate heat transfer boundary condition is applied as mentioned before. 
At $\mathrm{y}=\mathrm{H}_{\mathrm{h}},\left(\mathrm{H}_{\mathrm{h}}+\mathrm{t}\right)$

$-k_{j} \frac{\partial T_{j}}{\partial y}=-k_{s} \frac{\partial T_{s}}{\partial y}, \mathrm{~T}_{\mathrm{j}}=\mathrm{T}_{\mathrm{s}}$

Where $\mathrm{j}=\mathrm{h}, \mathrm{c}$ for hot and cold fluids respectively.

The above equations with their boundary conditions were solved using numerical program and the distributions of velocity, pressure and temperature were calculated, from which the pressure drop, effectiveness and other required parameters are calculated.

Heat exchanger effectiveness is the ratio of the actual heat transfer to the maximum possible heat that can be transferred:

$\varepsilon=\frac{q}{q_{\max }}$

Where

$\mathrm{q}_{\max }=\mathrm{C}_{\min }\left(\mathrm{T}_{\mathrm{hi}}-\mathrm{T}_{\mathrm{ci}}\right)$

And $\mathrm{q}=\mathrm{C}_{\mathrm{h}}\left(\mathrm{T}_{\mathrm{hi}}-\mathrm{T}_{\mathrm{ho}}\right)=\mathrm{C}_{\mathrm{c}}\left(\mathrm{T}_{\mathrm{co}}-\mathrm{T}_{\mathrm{ci}}\right)$

Where $\quad C_{h}=\dot{m} C p_{h} \quad$ and $\quad C_{c}=\dot{m} C p_{c}$

Total pressure drop across the heat exchange unit is:

$\Delta \mathrm{Pt}=\Delta \mathrm{P}_{\mathrm{h}}+\Delta \mathrm{P}_{\mathrm{c}}=\left(\mathrm{P}_{\mathrm{hi}}-\mathrm{P}_{\mathrm{ho}}\right)+\left(\mathrm{P}_{\mathrm{ci}}-\mathrm{P}_{\mathrm{co}}\right)$

To calculate the overall performance of a heat exchanger taken into consideration both the thermal and hydrodynamic performance a parameter called performance index is used which is the ratio of effectiveness to the total pressure drop [9]:

$$
\eta=\frac{\varepsilon}{\Delta P t}
$$

\section{3-3. Temperature dependent properties:}

In this paper the temperature dependent properties assumption will be studied. The equations (1) to (5) were solved based on the assumptions mentioned in section (2-1) with variable properties which are calculated using suitable relations as a function of temperature as indicated in the equations (11) to (14) below provides for density, specific heat, thermal conductivity and dynamic viscosity of water [1]. These formulae are implemented in the numerical computation and introduced to the main program by writing subroutines to calculate the properties of fluids at the end of each iteration based on the value of temperature.

$$
\begin{aligned}
& \rho(T)=\frac{a_{0}+a_{1} T+a_{2} T^{2}+a_{3} T^{3}+a_{4} T^{4}+a_{5} T^{5}}{1-a_{6} T} \\
& C p(T)=b_{0}+b_{1} T+b_{2} T^{2}+b_{3} T^{3} \\
& k(T)=c_{0}+c_{1} T+c_{2} T^{2}+c_{3} T^{3}+c_{4} T^{4} \\
& \mu(T)=d_{0} 10^{\left[d_{1} /\left(T-d_{2}\right)\right]}
\end{aligned}
$$


Note that except for the density of water, where the temperature is expressed in degree Celsius $\left({ }^{\circ} \mathrm{C}\right)$, each expression is given as a function of absolute temperature in Kelvin $(\mathrm{K})$. The constants in equations (11) to (14) are listed in Table 1 below:

Table 1 coefficients of temperature dependent formulae [1]

\begin{tabular}{|c|l|l|l|l|}
\hline $\mathrm{n}$ & \multicolumn{1}{|c|}{$\mathrm{a}_{\mathrm{n}}$} & \multicolumn{1}{|c|}{$\mathrm{b}_{\mathrm{n}}$} & \multicolumn{1}{c|}{$\mathrm{c}_{\mathrm{n}}$} & \multicolumn{1}{c|}{$\mathrm{d}_{\mathrm{n}}$} \\
\hline 0 & 999.8396 & 8958.9 & -0.8658 & $2.414 * 10^{-5}$ \\
\hline 1 & 18.22494 & -40.535 & 0.008574 & 247.8 \\
\hline 2 & $-7.9222 * 10^{-3}$ & 0.11243 & $-1.174 * 10^{-5}$ & 140 \\
\hline 3 & $-5.54485^{*} 10^{-5}$ & $-1.0138 * 10^{-4}$ & $-5.2597 * 10^{-9}$ & \\
\hline 4 & $1.49756^{*} 10^{-7}$ & & $1.3211 * 10^{-11}$ & \\
\hline 5 & $-3.933 * 10^{-10}$ & & & \\
\hline 6 & $1.816^{*} 10^{-2}$ & & & \\
\hline
\end{tabular}

The fluid used in this paper is water flow through square channels. The dimensions of channels are: channel height $\mathrm{H}_{\mathrm{h}}=\mathrm{H}_{\mathrm{c}}=100 \mu \mathrm{m}$, channel width $\mathrm{W}_{\mathrm{ch}}=100 \mu \mathrm{m}$, wall thickness $t=50 \mu \mathrm{m}$, length $\mathrm{L}=10 \mathrm{~mm}$. The inlet velocity ranged $(0.2-1) \mathrm{m} / \mathrm{s}$, inlet temperatures of hot and cold fluids are $\mathrm{T}_{\mathrm{hi}}=373 \mathrm{~K}, \mathrm{~T}_{\mathrm{ci}}=293 \mathrm{~K}$.

The material of solid wall chosen is silicon with the following properties: $\rho_{\mathrm{s}}=2230$ $\left(\mathrm{kg} / \mathrm{m}^{3}\right), \mathrm{Cp}_{\mathrm{s}}=712(\mathrm{~J} / \mathrm{kg} . \mathrm{K})$ and $\mathrm{k}_{\mathrm{s}}=148(\mathrm{~W} / \mathrm{m} . \mathrm{K})$.

\section{Numerical model:}

A finite volume method (FVM) is used to convert governing equations to algebraic equations accomplished using an "upwind" scheme. The SIMPLE algorithm is used to enforce mass conservation and to obtain the pressure field. The segregated solver is used to solve the governing integral equations for the conservation of mass, momentum and energy [10]. A mesh was generated by descretizing the computational domain (two channels and separating wall) and a mesh independent study was made to investigate the dependency of numerical solution accuracy on the grid size.

The convergence criteria to control the solution for momentum and energy equation were set to be less than $10^{-6}$.

\section{Results and discussion:}

To check the validity of the present numerical model used to simulate a PFMCHE with variable properties assumption the results of the present numerical model are compared with that of reference [1]. The problem presented in [1] is a heat sink composed of rectangular microchannels. The hydraulic diameter is $86 \mu \mathrm{m}$ and length of $10 \mathrm{~mm}$, the inlet temperature is $293 \mathrm{~K}$ and constant heat flux of $90\left(\mathrm{~W} / \mathrm{cm}^{2}\right)$ acted on the bottom walls of channels with temperature dependent properties of water. The problem is simulated by the present numerical model and the results were compared with the results presented in [1] the comparison is shown in figures 3 to 4. 
Fig. 3 shows the distribution of static pressure drop along the microchannels under consideration at $\operatorname{Re}=399$ obtained using present numerical model and that obtained by [1]. From this figure one can see that, the agreement is acceptable since the error between results is $2.9 \%$.

Distribution of bulk temperature of fluid along channel as a comparison between numerical results of present model and numerical results of [1] at $\mathrm{Re}=141$ is indicated in Fig. 4. From this figure the agreement between present model and model presented in [1] is also acceptable since the mean percentage error between two results is $0.9 \%$.

From the previous comparisons it can be concluded that the present model can be used accurately to simulate a PFMCHE with the assumption of temperature dependent properties.

Fig. 5 shows the variation of pressure drop ratio (ratio of pressure drop at variable properties to the pressure drop at constant properties $\left.\left(\frac{\Delta P_{v}}{\Delta P_{c}}\right)\right)$ with inlet velocity. From this figure it can be seen that, the ratio of pressure drop is lower than one for all range of selected velocity which means that, the pressure drop with variable properties is lower than that for constant properties because the decrease in viscosity of cold fluid is larger than the increase in viscosity of hot fluid as can be seen from figure 6 which represents the variation of water viscosity with temperature [11]. The percentage difference in pressure drop between the two approaches is indicated in Table 2 below for different values of flow velocity.

Table 2 percentage difference in pressure drop of two approaches

\begin{tabular}{|c|c|}
\hline Inlet velocity $(\mathrm{m} / \mathrm{s})$ & $\frac{\Delta P_{c}-\Delta P_{v}}{\Delta P_{c}} \times 100 \%$ \\
\hline 0.2 & $16.84 \%$ \\
\hline 0.4 & $12.9 \%$ \\
\hline 0.6 & $10.33 \%$ \\
\hline 0.8 & $8.63 \%$ \\
\hline 1 & $7.44 \%$ \\
\hline
\end{tabular}

Where $\Delta \mathrm{P}_{\mathrm{c}}$ is the pressure drop calculated based on the constant properties and $\Delta \mathrm{P}_{\mathrm{v}}$ is the pressure drop calculated according to the variable properties.

From these results the percentage reduction in pressure drop associated with using the temperature dependent properties approach is decreased with increase the velocity of flow due to the small change in fluid's temperatures associated with higher velocity which leads to small change in the properties of fluids.

Fig. 7 shows the distribution of bulk temperature of hot fluid for two approaches (constant and temperature dependent properties). From this figure it can be seen that, the bulk temperature of hot fluid based on variable properties assumption is smaller than that for constant properties due to the difference in thermal conductivity and other fluid 
properties between two approaches. This difference in bulk temperature leads to increase in the thermal performance of the heat exchanger.

Fig. 8 shows the variation of the effectiveness ratio (ratio of effectiveness at variable properties to the effectiveness at constant properties $\left.\left(\frac{\varepsilon_{v}}{\varepsilon_{c}}\right)\right)$ with inlet velocity. From this figure it can be seen that, the effectiveness ratio is more than one for all range of selected velocity which is mean that, the effectiveness with temperature dependent properties is larger than that for constant properties. It's clear that the difference between the effectiveness for two approaches is small due to small changes in temperatures of two fluids. The difference in effectiveness between two approaches for different values of inlet velocity is listed in Table 3 below:

Where $\varepsilon_{\mathrm{v}}$ is the effectiveness of a PFMCHE calculated based on the variable properties approach and $\varepsilon_{\mathrm{c}}$ is the effectiveness of a PFMCHE calculated based on the constant properties model.

Table 3 Difference in effectiveness of constant and variable properties approaches

\begin{tabular}{|c|c|}
\hline Inlet velocity $(\mathrm{m} / \mathrm{s})$ & $\frac{\varepsilon_{v}-\varepsilon_{c}}{\varepsilon_{c}} \times 100 \%$ \\
\hline 0.2 & $3.88 \%$ \\
\hline 0.4 & $3.87 \%$ \\
\hline 0.6 & $3.38 \%$ \\
\hline 0.8 & $3.26 \%$ \\
\hline 1 & $2.83 \%$ \\
\hline
\end{tabular}

From the data shown in table 3 above the difference between the two approaches decreased with increasing inlet velocity since with increasing the flow velocity there is no large change in temperature of two fluids and as a result the change in fluid's properties is decreased.

Variation of performance index ratio $\left(\frac{\eta_{v}}{\eta_{c}}\right)$ with inlet velocity is illustrated in Fig. 9.

From this figure, the ratio of performance index is more than one for all range of selected velocity which means that, using the temperature dependent assumption leads to larger overall performance compared with using constant properties. This is attributed to increasing the effectiveness and decreasing the pressure drop required to circulate two fluids. Also one can see the gain in performance index decreased with increasing velocity of flow due to the small increment in effectiveness and small reduction in pressure drop. Table 4 below indicates the percentage increase in performance index when using variable properties and constant properties.

Table 4 Percentage difference in performance index

for two approaches

\begin{tabular}{|c|c|}
\hline Inlet velocity $(\mathrm{m} / \mathrm{s})$ & $\frac{\eta_{v}-\eta_{c}}{\eta_{c}} \times 100 \%$ \\
\hline
\end{tabular}


University of Thi-Qar Journal Vol.10 No.4 Dec 2015

Web Site: https://jutq.utq.edu.iq/index.php/main Email: journal@jutq.utq.edu.iq

\begin{tabular}{|c|c|}
\hline 0.2 & $23.66 \%$ \\
\hline 0.4 & $18.33 \%$ \\
\hline 0.6 & $14.84 \%$ \\
\hline 0.8 & $13.63 \%$ \\
\hline 1 & $12.12 \%$ \\
\hline
\end{tabular}

Where $\eta_{\mathrm{v}}$ is the performance index calculated according to variable properties approach and $\eta_{\mathrm{c}}$ is the performance index calculated according to the constant properties approach.

Fig. 10 indicates the variation of heat transfer rate ratio $\left(\frac{q_{v}}{q_{c}}\right)$ with inlet velocity. From this figure it can be seen that, the ratio of heat transfer rate is more than one for all range of velocity which means that, the amount of heat transfer for variable properties is higher than its value corresponding to the constant properties assumption. Also the difference in heat transfer for the two approaches increases with increasing flow velocity due to higher increase in thermal conductivity of cold fluid compared with decreasing in conductivity of hot fluid.

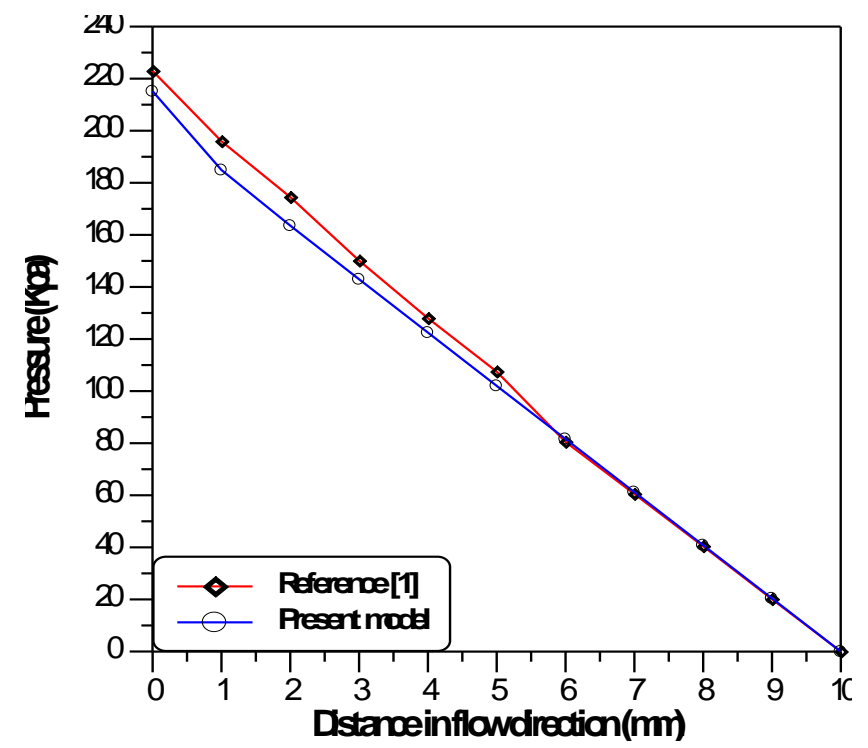

Fig. 3 Comparison between the pressure distributions along heat sink for present model and that obtained by $[1](\mathrm{Re}=399)$

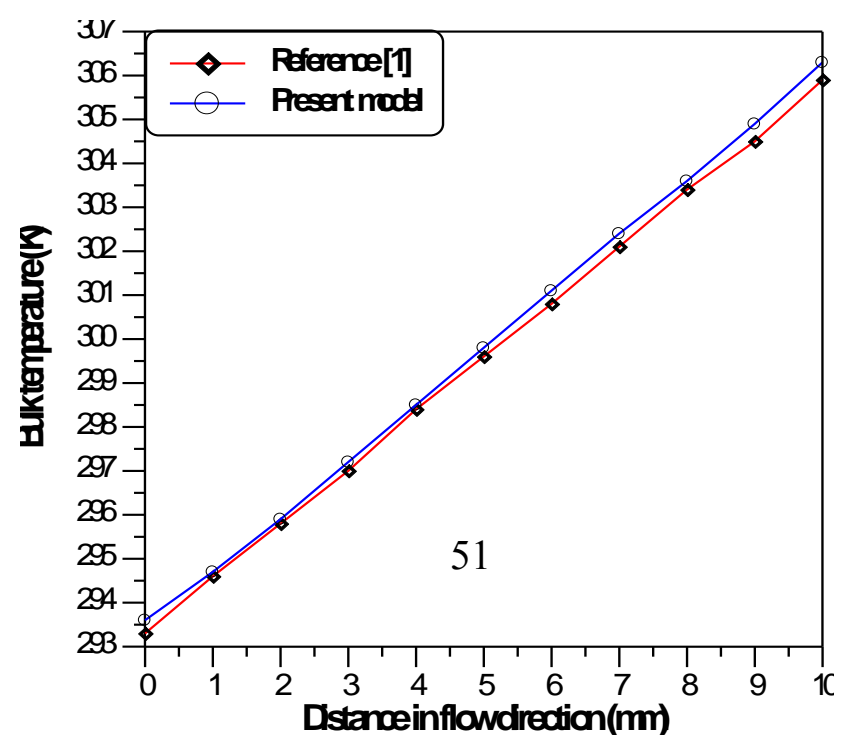




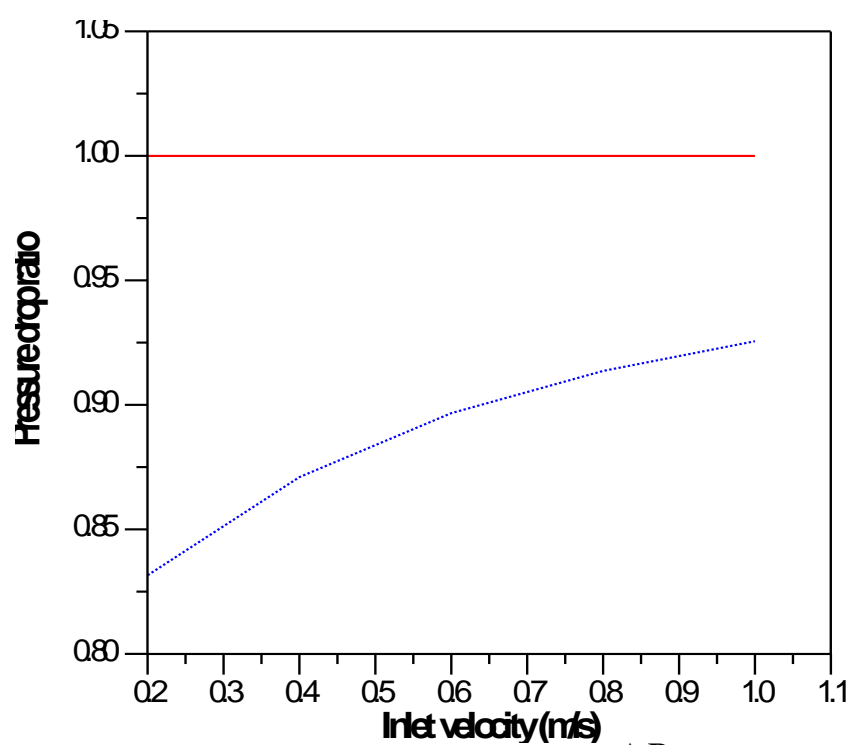

Fig. 5 Variation of pressure drop ratio $\left(\frac{\Delta P_{v}}{\Delta P_{c}}\right)$ for constant and variable properties assumptions

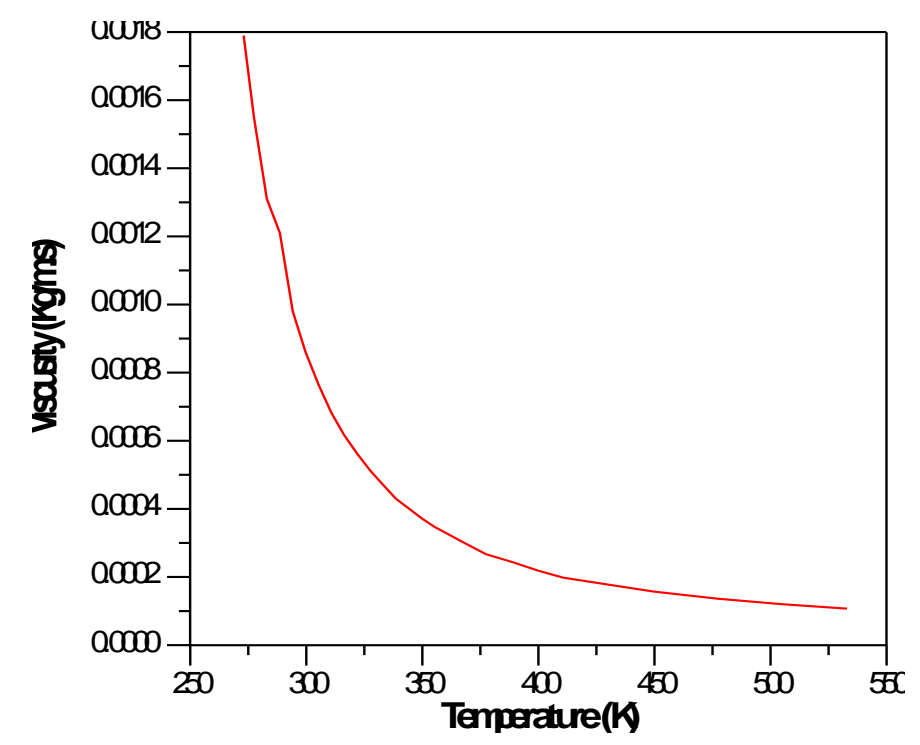

Fig. 6 Variation of water viscosity with temperature [11]

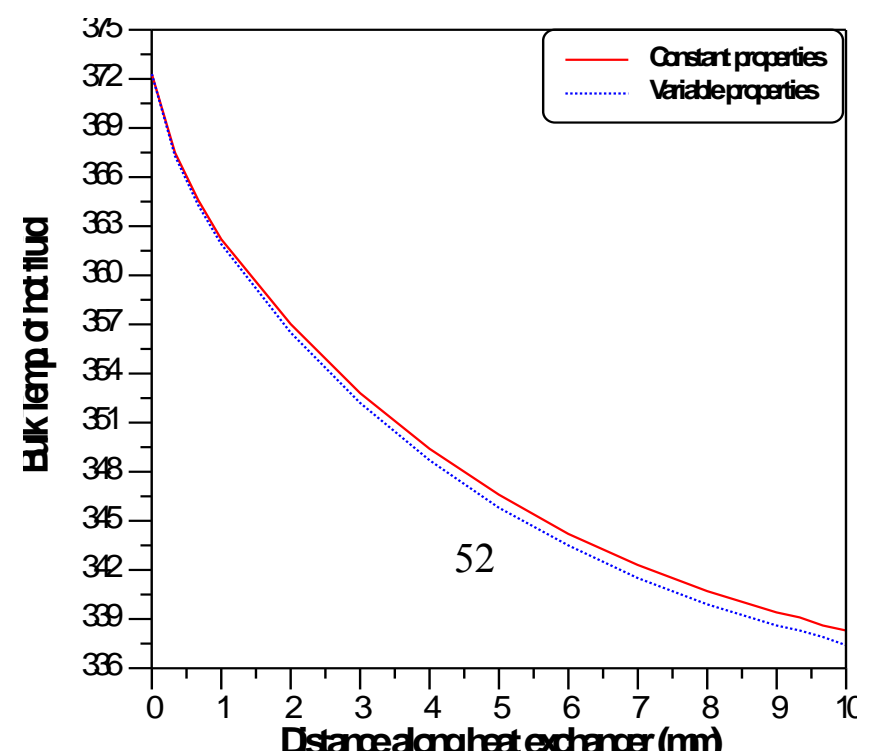




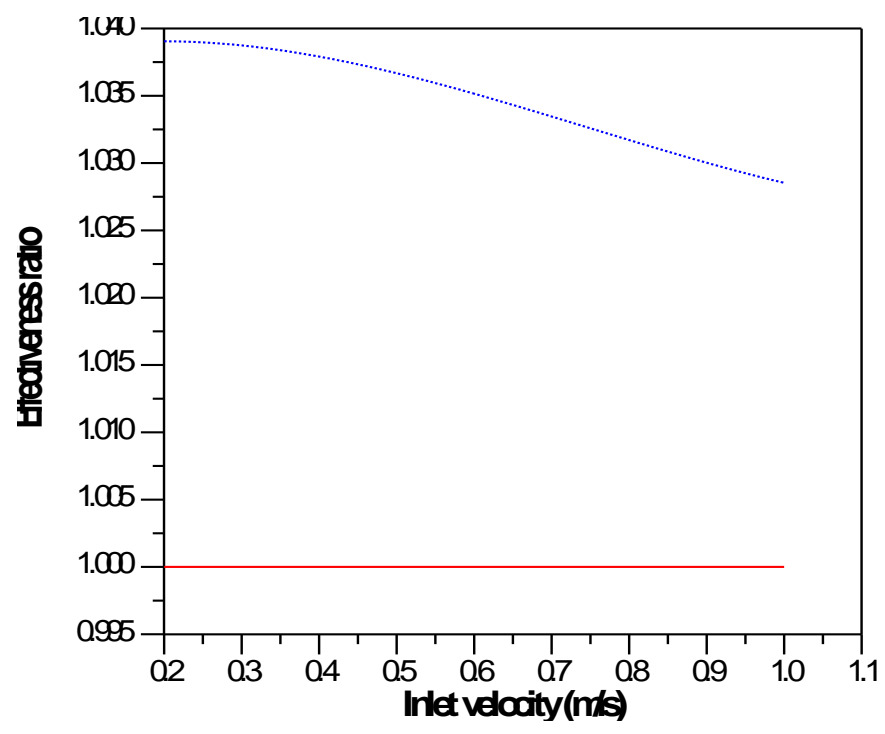

Fig. 8 variation of effectiveness ratio $\left(\frac{\varepsilon_{v}}{\varepsilon_{c}}\right)$ with inlet velocity

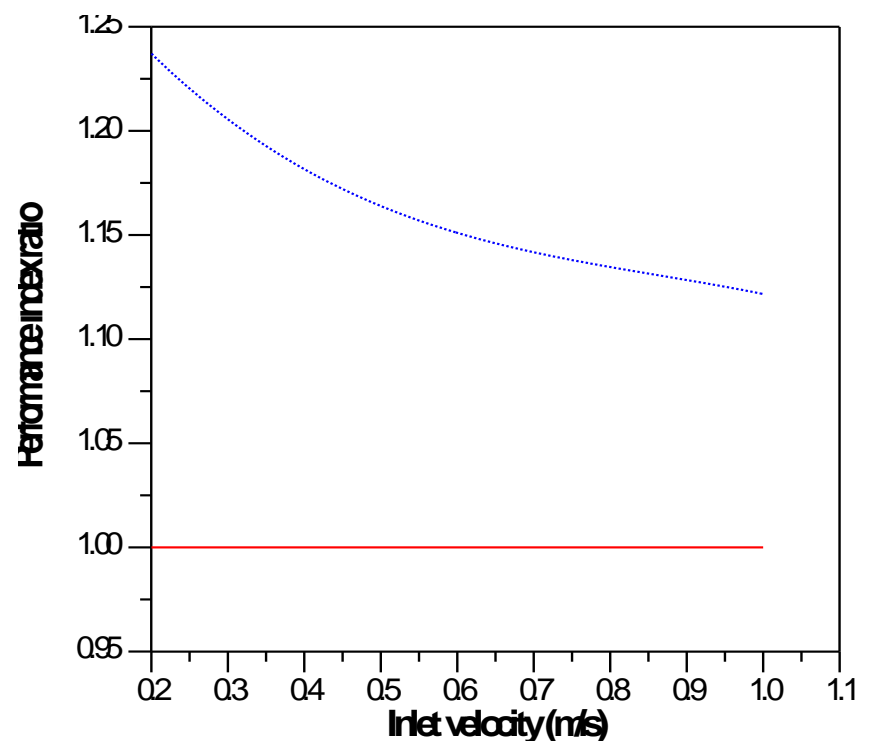

Fig. 9 Variation of performance index ratio $\left(\frac{\eta_{v}}{\eta_{c}}\right)$ with inlet velocity

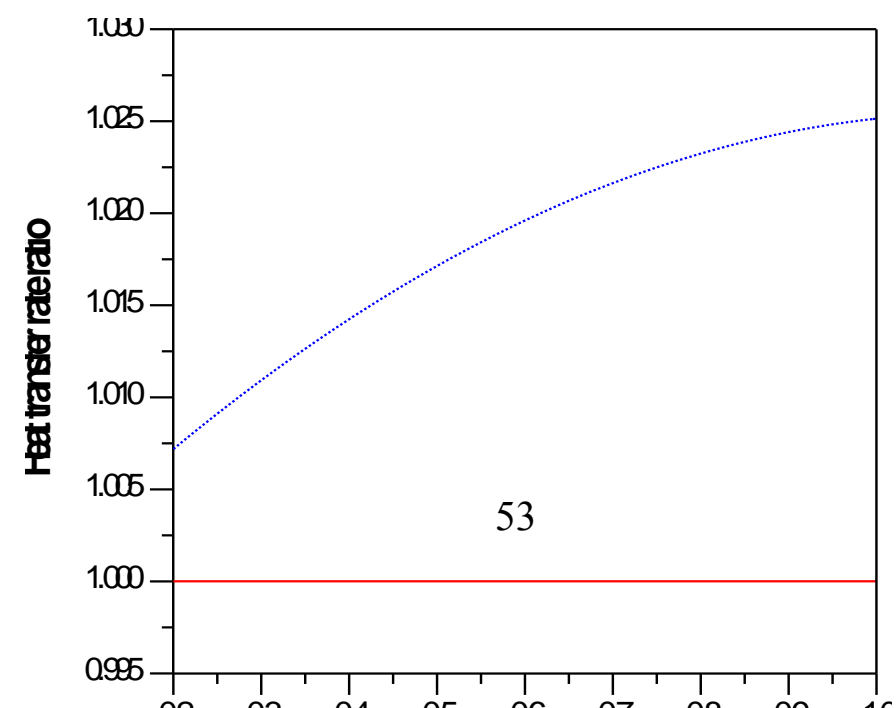




\section{Conclusions:}

The parallel flow microchannel heat exchanger is numerically simulated in this paper to investigate the effect of treating the properties of fluids as temperature dependent compared with constant properties assumption. From the results obtained The following conclusions can be drawn:

1- Temperature dependent properties assumption gives lower pressure drop compared with constant properties.

2- Also the temperature dependent properties assumption leads to obtain higher thermal performance, since the effectiveness and heat transfer rate for variable properties are higher than its values corresponding to the constant properties assumption.

3- The overall performance represented by the performance index for variable properties is higher than that for constant properties.

\section{References:}

[1] Dong Liu , Poh-Seng Lee, " Numerical investigation of fluid flow and heat transfer in microchannel heat sinks ", ME 605 Convection of Heat and mass, ASME, West Lafayette, USA, 2003.

[2] Hussien Albakhit, Ahmad Fakheri, "A hybrid approach for full numerical simulation of heat exchangers", ASME Heat Transfer Summer Conference, San Francisco, CA, USA, 2005.

[3] Nonino C., Del Giudice S., Savino S., "Temperature dependent viscosity effect on laminar forced convection in the entrance region of straight ducts", Int. J. of Heat and Mass Transfer, Vol. 49, pp. 4469 - 4481, 2006.

[4] Del Giudice S., Nanino C., Savino S., " Effect of viscous dissipation and temperature dependent viscosity in thermally and simultaneously developing laminar flows in microchannels ", Int. Journal of Heat and Fluid flow, 28, pp. 15 - 27, 2007.

[5] Nitin P., Gulhane, Shripad P., Mahulikar, "Variation in gas properties in Laminar micro - convection with entrance effect", Int. J. of Heat and Mass Transfer, Vol. 52, pp. 1980 1990, 2009.

[6] Mushtaq I. Hasan, Mahmood Yaghoubi, Abdul Muhsen A. Rageb, " Improving thermal performance of a counter flow microchannel heat exchanger by using nanofluid", Fourth International Conference on Thermal Engineering: Theory and Applications, January 12 14, 2009, Abu Dhabi, UAE. 
[7] Merle C. Potter, John F. Foss, "Fluid Mechanics", Great Lakes Press, INC. Okemos, MI 48864, 1982.

[8] Frank M. White, "Viscous Fluid Flow", Second Edition, McGraw -Hill, Inc., 1991.

[9] Mushtaq I. H., A. A. Rageb, M. Yaghoubi, Homayon H., " Influence of channel geometry on the performance of counter flow microchannel heat exchanger", Int. Journal of thermal sciences, Vol. 48, 1607-1618, 2009.

[10] Versteeg H. K., Malasekera W., "An introduction to computational fluid dynamics (The finite Volume method)", Addison Wesley Longman Limited, 1995.

[11] Holman J. P., "Heat transfer", SI Metric edition, McGraw - Hill Book Company, 1989. 